\title{
Indices of water availability assessment on hydrological basins: a case in Mexico
}

\author{
I. Velasco \\ Hydrology Department, Mexican Institute of Water Technology, Mexico
}

\begin{abstract}
Water use and demand are increasing sensitive; all the productive sectors require bigger volumes with a minimal quality to complete the expectations in the requirements of food, goods, services and manufactured products.

The hydrological systems are under increasing pressure and in Mexico City this need has led to severe crises owing to the inadequacy of the natural water supply to meet this demand. Particularly, water over-assignments phenomenon is present; the assignment to some users with volumes that overcome the natural capacity, due mainly to ignorance about the real watershed capacity, so these volumes lead to stressing of the hydrological systems, creating dangerous situations because the conflicts and social unbalances are increased, especially during shortage periods. Given the complexity and uncertainty on hydrologic phenomenon and the variability in time, if it is not properly assessed it can drive to over evaluating the water supply capacity and then to the creation of false expectations that potentially cause a crisis and negative impacts because of water inadequacy.

In the face of this dilemma, it is essential to carry out hydrological balances keeping in mind that watershed is the unit of analysis, and considering the diverse water uses, individually and as a whole in order to evaluate the potentiality, as objectively as possible, of the water available related to water demand. This allows us to estimate the level of relative availability, and on this basis, to improve water planning with a reasonable risk of falling under conditions such that imply over exploitation and committing their sustainability. This acquires special importance for basins where hydrometric information is scarce or null, and then one has to apply indirect methods for water availability estimation; the results are expressed graphically as a "semaphore plane".

Keywords: hydrologic balance, water availability, water resources assessment.
\end{abstract}




\section{Introduction}

Water demand has a continued growth, but not its availability.

To achieve a regional balanced development of the activities that demand water as a basic input, it is necessary that water demands are in agreement with water availability. To balance both components is not always an easy task, because of the multiple water uses (agriculture, domestic use, aquaculture, industry, energy generation, etc.), and because frequently the users do not have a registration or official assignment with the correct physical location and the volumes to use; on the other hand, the offer is also frequently only supposed, since measurements are not made, neither controlled due to, among other factors, the lack or inadequacy of the hydrometric network, the lack of economic resources to assist this activity, and the rural and isolated control points, etc.

Nevertheless, the environmental sustainability, considering the water as the main axis, depends on the knowledge about the certainty of the availability of the resource, as well as its demand, in order to achieve an exploitation and rational use without causing unnecessary water stress and without committing the stability and future development.

\section{Technical and institutional basis}

Estimating the available water volumes in Mexico on an annual basis, is based on an official standard [1, 2], relative to the water conservation, which establishes the specifications and the methodology for determining the annual average availability of the national waters on a hydrological basin as a unit of analysis.

Briefly, the method is based in estimating the balance between demand and supply, when both components are calculated separately, with the considerations for each case. For the supply, available hydrometric information is used, registered as monthly runoff volumes measured in specific places, usually at the basin or sub basin exit, where there is a reservoir, a diversion dam or a hydrometric station. To these volumes are added the upstream used volumes within the basin, to obtain a total runoff volume. On the other hand, the demand is considered from the last or the lowest delivery point toward upstream, in order to accumulate the partial volumes and then to obtain the whole demand to the hydrological system.

Starting from knowing the assigned water and the runoff in a final point of the sub basin $i$, one has that [2]:

$$
A_{B_{i}}=C_{P_{i}}+A_{R_{i}}+R_{i}+I_{i}-\left(U c_{i}+E_{V_{i}}+E_{X_{i}}+\Delta V_{i}\right)
$$

where:

$A_{B i} \quad$ runoff toward downstream of the sub basin

$C_{P i} \quad$ runoff or water contribution within the sub basin

$A_{R i} \quad$ runoff from upstream sub basin(s) 
$R_{i} \quad$ water returns within the sub basin

$I_{i} \quad$ water importation from other basin(s)

$U c_{i} \quad$ water use (consumptive use) within the sub basin

$E v_{i} \quad$ water evaporation from reservoirs

$E_{x i} \quad$ water exportation to other basin(s)

$\Delta V_{i} \quad$ annual volume variation in stored water (reservoirs) $\left(V_{2}-V_{l}\right)$

This leads to estimating the volume that is available in the final point of the sub basin, which is the same that enters to the immediately downstream basin.

\subsection{Reserved volumes estimation within the sub basin}

The downstream reserved volume, $R_{X Y}$, for a given sub basin $X$, is the fraction of the runoff that comes out at the end of the area, such that it contributes to satisfy the extractions and demands of the next downstream sub basin $Y$; and reserved volume for sub basin $X, R_{X X}$, is that which contributes to the satisfaction of demands inside the same sub basin $X$. The demand estimation is carried out from downstream toward upstream.

\subsection{Available volumes in each sub basin}

Water volumes available at the end of a sub basin $\left(D_{X Y}\right)$, can be estimated as the difference of $A_{B i}$, the runoff downstream, minus the reserved volumes, $R_{X Y}$, those volumes which sub basin $X$ contributes to satisfy the demands of sub basin $Y$. This way, the available volumes from sub basin $X$ to sub basin $Y$ are:

$$
D_{X Y}=A_{B X}-R_{X Y}
$$

Similarly, the remainder water volumes, available for sub basin $\mathrm{X}$ itself are:

$$
D_{X X}=C_{P X}-R_{X X}
$$

In order to classify the sub basins according to water available, the term relative availability coefficient $\left(D r_{i}\right)$ is used, which is expressed by the equation:

$$
D r_{i}=\frac{C p_{i}+A r_{i}}{U c_{i}+V c_{i}}
$$

where $V c_{i}$ is the committed water volume that is equal to the reserved volume from sub basin $X$ for a sub basin $Y\left(R_{X Y}\right)$, downstream; although at the moment it is not contemplated as such, future versions of $R_{X Y}$ should include the environmental flow (or ecological volume) focused to the preservation of natural flora and fauna, especially on the river beds.

In accordance with the range where estimated $D r_{i}$ is located, the respective sub basin will be classified following the distribution shown in Table 1 . The $D r_{i}$ 
values are conventional and they show the proportion between water available (the offer) and water requirements (the demand).

Table 1: Conventional characteristic of the relative availability coefficient $D r_{i}$.

\begin{tabular}{|c|c|c|c|}
\hline Range & code & Color & Description \\
\hline$D r_{i}<1.4$ & 1 & Red & D(eficit) \\
\hline $1.4<D r_{i}<3.0$ & 2 & Yellow & E(quilibrium) \\
\hline $3.0<D r_{i} \leq 9.0$ & 3 & Green & R(eserve) \\
\hline $9.0<D r_{i}$ & 4 & Blue & A(bundance) \\
\hline
\end{tabular}

Thus, $D r_{i}$ is a conventional measure of water stress that is estimated for a sub basin, and means the commitment level of water assignments related to natural water volumes given by rain and runoff.

\section{Application case}

The case here is presented is related to the San Pedro River Basin, located in the Center-West of Mexico (figure 1), that includes approximately $28,563 \mathrm{~km}^{2}$, and is formed by 11 well defined sub basins, two of which are closed, with no connection or exit, and the other nine are connected to each other downstream, having a final point at the discharge to the Pacific Ocean (figure 2).

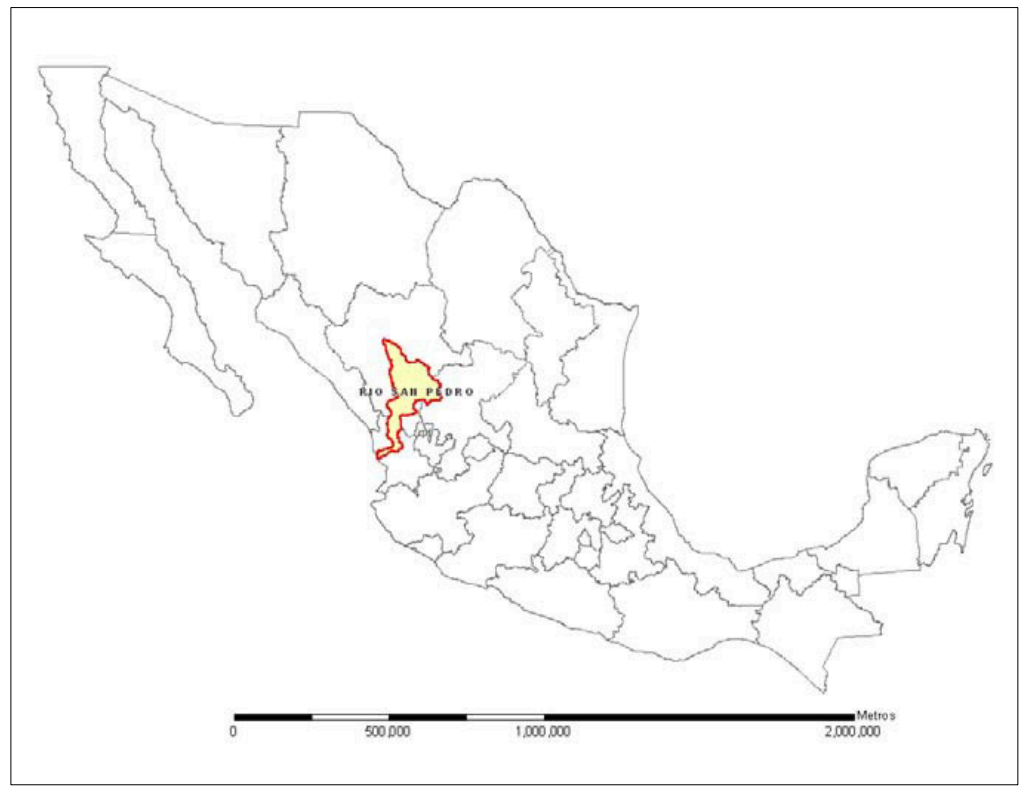

Figure 1: $\quad$ Location of the San Pedro River Basin in Mexico. 


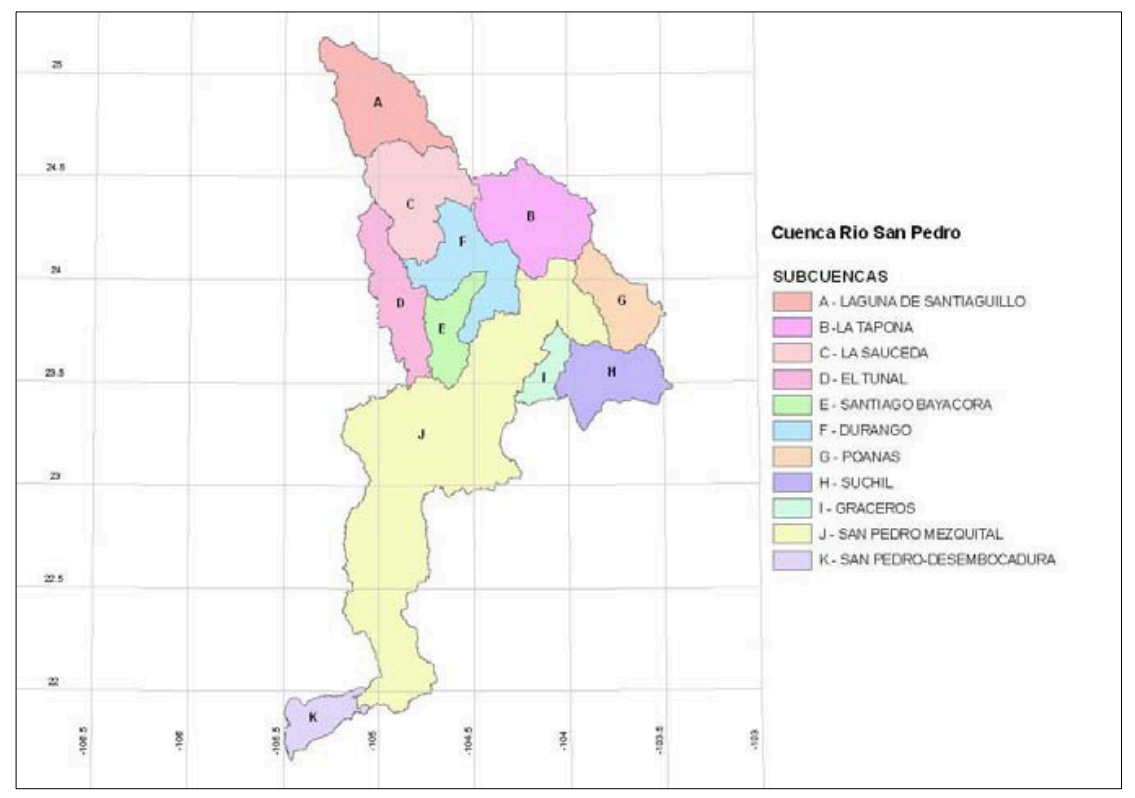

Figure 2: $\quad$ Sub basins within the San pedro River Basin.

Although a defined hydrographic network exists, which includes main and tributaries streams in all the sub basins that discharge to San Pedro River, which finally ends in the sea, the hydrometric information is not as complete as would be desirable, neither has it the record longitude and homogeneity since the dynamics of the basin has changed now that reservoirs, diversion works, and other works have been built which alter the old mesurements sites, or they have disappeared or been cancelled, which all results in that the data cannot be used efficiently as a direct information source.

In those cases, it is necessary to use the indirect method to estimate the surface water contributions; it consists basically on transporting the runoff coefficients, $C E$, from physiographical neighbor and similar sub basins, which have enough hydrometric records. The $C E$ is the relationship measured (runoff)/rainy volume, both for the same period. That gives a dimensionless fraction as a result, in the interval 0.03 at 0.85 , which indicates the proportion of the rain volume that flows and is measured in the gauging site or hydrometric point; so, the flatter and covered (vegetation) the surface, the smaller the $C E$; then, this parameter is also an indirect measure of the covering and slope.

Certainly, homogeneity among sub basins is something relative and subjective, since the differences can be minimum but lead to different effects, for what the analyst judgement and experience are decisive.

For this basin, the application refers exclusively to surface water, because groundwater is not significant, although the Mexican Standard also understands groundwater and its interrelation with surface water. 
For many Mexican river basins, mainly the most exploited, for many years the water authorities have established and sent ordinances which prohibited and/or limited the water extraction and/or assignment in bigger volumes in order to avoid demand exceeding availability, with a possible crisis for water inadequacy. For this basin, such an official ordinance has existed since 1955 [3]; the value and importance of these ordinances have been decisive to avoid or to palliate the conflicts, especially when water scarcity periods have occurred. These water regulations are very effective because in Mexico the water (and in general all the natural resources) are the nation's property, and not particularly those of the separate States which are part of the country.

Table 2 shows the main characteristics of the eleven sub basins that compose the San Pedro River Basin, as well as the basic outcomes of the water balance, expressed by the $D r_{i}$.

Table 2: Main characteristics of the sub basins and the hydrological balance.

\begin{tabular}{|c|r|r|r|r|r|r|c|}
\hline \multirow{2}{*}{$\begin{array}{c}\text { Sub } \\
\text { basin }\end{array}$} & \multirow{2}{*}{$\begin{array}{c}\text { Area, } \\
\mathrm{km}^{2}\end{array}$} & \multicolumn{4}{|c|}{ Water Volumes, $\mathrm{hm}^{3}$} & \multirow{2}{*}{$D r_{i}$} & \multirow{2}{*}{ Code } \\
\cline { 3 - 6 } & & $U_{C}$ & $C_{P}$ & $A_{B}$ & $D_{X Y}$ & & \\
\hline $\mathrm{A}$ & 2,362 & 8 & 125 & 35 & 35 & 1.39 & $\mathrm{D}$ \\
\hline $\mathrm{B}$ & 2,594 & 3 & 88 & 85 & 85 & 31.09 & $\mathrm{~A}$ \\
\hline $\mathrm{C}$ & 2,452 & 16 & 129 & 76 & 50 & 1.64 & $\mathrm{E}$ \\
\hline $\mathrm{D}$ & 1,800 & 0.297 & 139 & 130 & 87 & 2.66 & $\mathrm{E}$ \\
\hline $\mathrm{E}$ & 1,092 & 24 & 82 & 51 & 34 & 1.71 & $\mathrm{E}$ \\
\hline $\mathrm{F}$ & 2,171 & 97 & 94 & 254 & 63 & 3.01 & $\mathrm{R}$ \\
\hline $\mathrm{G}$ & 1,400 & 35 & 44 & 2 & 1.6 & 1.04 & $\mathrm{D}$ \\
\hline $\mathrm{H}$ & 1,733 & 13 & 36 & 23 & 21 & 2.45 & $\mathrm{E}$ \\
\hline $\mathrm{I}$ & 597 & 0.144 & 10 & 9 & 9 & 10.96 & $\mathrm{~A}$ \\
\hline J & 11,521 & 15 & 2,509 & 2,782 & 2,314 & 12.92 & $\mathrm{~A}$ \\
\hline K & 842 & 221 & 272 & 2,833 & 253 & 13.79 & $\mathrm{~A}$ \\
\hline TOTAL & 28,563 & 433 & 3,528 & & 2,953 & & \\
\hline
\end{tabular}

The graphical presentation of these results is shown in figure 3, called the semaphore plane, where using contrasting and conventional colors it is simple to appreciate more qualitatively and objectively the concept of relative water availability.

This way, in a first approach, this graphical result is useful so that the analysts confirm the truthfulness of the results with the reality, and also to improve the perception and sensibility of the water users in order to inform them that this is a limited and scarce resource and that its use should be made with efficiency and respecting the rights of all the users to water access, and the downstream committed volumes as well as the priorities in water use. 


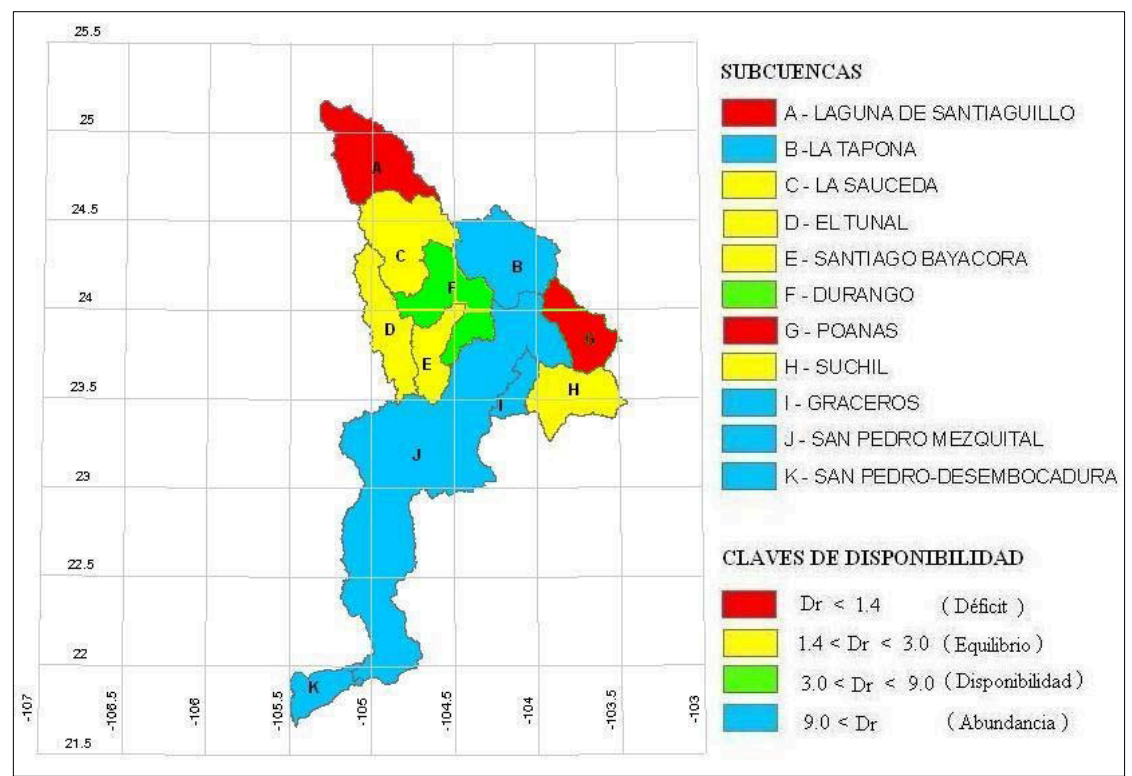

Figure 3: Semaphore map on relative water availability.

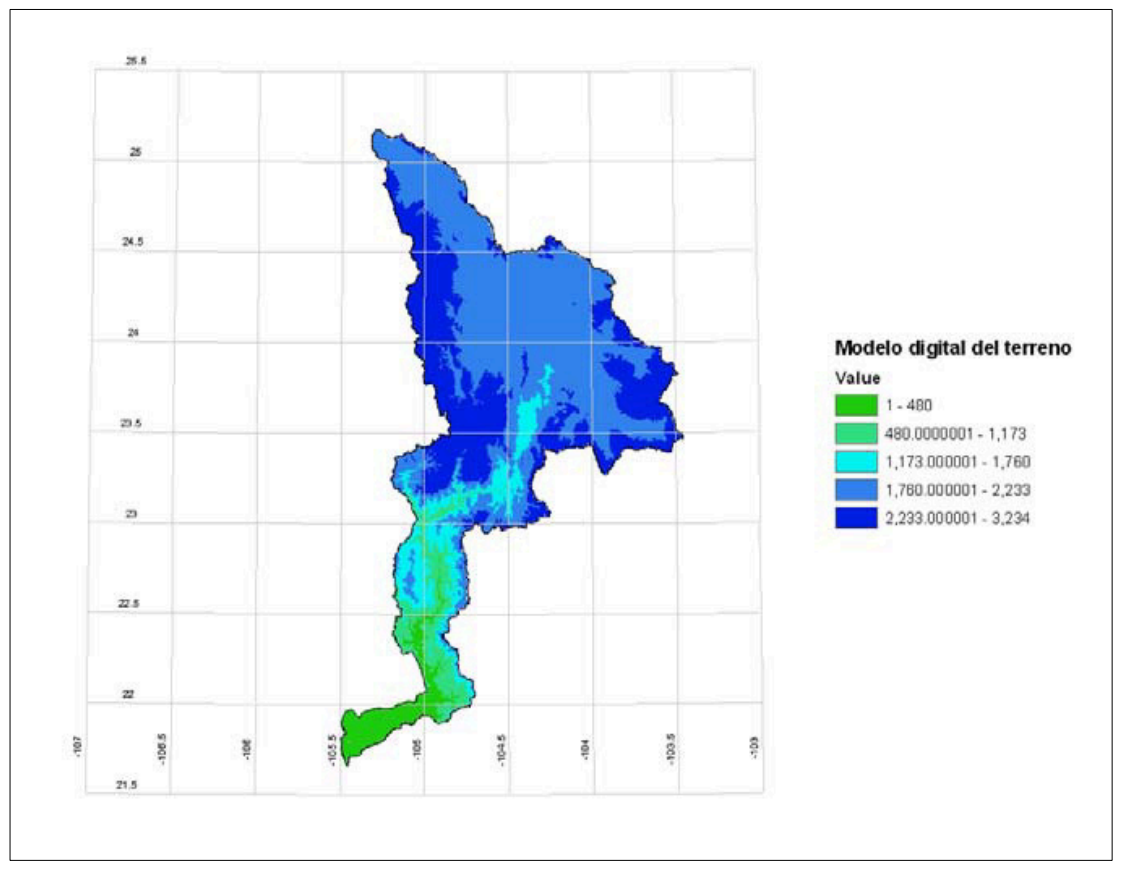

Figure 4: Digital terrain model, in meters above sea level. 
This perception is supplemented and improved if the water availability results are related to other physical aspects of the basin such as topography expressed, for example, through digital terrain models (figure 4), as well as isohyetal maps (figure 5); both concepts help for a better understanding of the occurrence and physical rain distribution on the area, as well as the reason why unauthorized or bigger water volumes are not be used because downstream commitments and other users exist and have the same water rights.

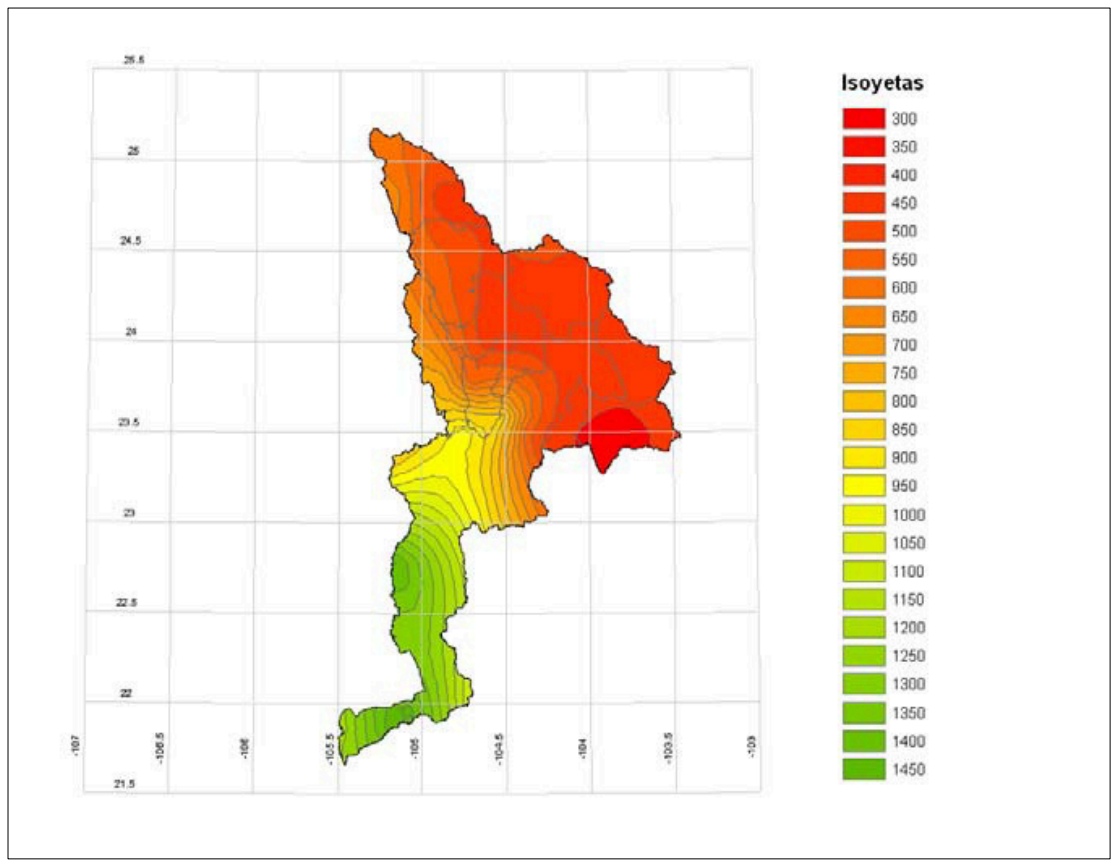

Figure 5: Annual isohyetal map, in millimeters, during the 1980-2001 period.

It should be kept in mind that $D r_{i}$ is just a conventional index and it seeks to indicate the degree of water stress or use, commitment or exploitation of the available resource; therefore, it is important to consider that mainly in the lower ranges (deficit, equilibrium, and reserve) the index evaluation is very sensitive to the change in one or both components (supply and demand), so still having a dimensionless numeric value, it is not definitive, since if the water balance evaluation or upgrade is made as is recommended i.e. every three years, it is very possible that there should be some changes from one range to another.

That is why it is important to have good hydrometric, meteorological information, and details of the demands.

Also, regarding the relative $D r_{i}$ index, its interpretation should be critical and analytic, because its value can be deceiving or confused: when the results show an abundance of water and indicate that the supply is greater than demand, but, 
due to the marked regional low water periods, if there is not way to retain and conserve the water through reservoirs or lakes to use it when it is required and there is no rain season, then such abundance is fictitious because monsoon lasts a short period, no more than four months.

To obtain the isohyetal lines, monthly data there analyzed the rain records in meteorological stations that cover the basin during the period 1980-2001, which made it possible to homogenize the information. So, the used meteorological information is appropriate because, besides its homogeneity, it covers 20 years as the Standard indicates, and is representative of the real basin conditions.

Although the hydrological network is well defined, it was not always possible to obtain the suitable information due to the heterogeneity of the records. There are in the basin several reservoirs with their respective hydrometric records: inputs and extractions [4], and in those cases it was possible to estimate the total runoff (including the used volumes upstream of the reservoir), as well as to obtain the runoff coefficients $C E$ which were used because of the fact that in the neighboring sub basins hydrometric records do not exist, or they are not enough nor appropriate. In this case, homogeneity among sub basins is considered appropriate since the vegetation, topography, and climate conditions are similar, so there are no significant differences; and then, transferring runoff coefficients from one area to another is considered a reasonable process.

Nevertheless, there is an aspect that requires special attention, and its carefulness will be very useful for the next Standard upgrades [1]: water demand and commited volumes. In Mexico, since some years ago, the Water Rights Public Registration (REPDA in Spanish), has been implemented as the legal instrument that allows to register all the water users and uses, which works as an inventory, evaluation and management tool. The potential of this tool is very positive, although the first version has some frequent flaws, like the water demand volumes or water rights location because the registered geographical coordinates, frequently not verified, as well as the possible typing errors, lead to wrong data of the distribution and geographical location; that means that they fall outside of the true sub basin, and that contributes to uncertainty and errors in the water demand accounting which affects the balance giving possible errors in the results.

\section{Conclusions}

The obtained results of this application are appropriate with the observed reality, so this fact allows us to affirm that the procedure is correct. The results are annual, but we are already working in adapting them to a monthly scale, which is important because the basin, as almost the whole country, has a summer season rain regime of a monsoon type, from July to October in which $80 \%$ of total rain occurs, so its intensity is high and frequently torrential. Then, there is a marked period of low water runoff during which the available water volumes can be lower than demands. 
In complement to the purely hydrological calculation, complementary aspects such as the topographical, meteorological, demographic, communication network, and agrological aspects are of high utility in order to make the results more valuable, and then to enrich the vision and to improve objectively the natural hydrological environment vision as a whole.

\section{Acknowledgements}

This work derives from the project "Estudio para determinar la disponibilidad media anual de las aguas nacionales superficiales en las cuencas de las Regiones Hidrológicas 10 y 11, Pacífico Norte" (Surface Nacional Water Assessment Study, for the Hydrological Regions 10 and 11, Northern Pacific, developed by the Mexican Institute of Water Technology, for the National Water Commission of Mexico).

\section{References}

[1] CNA, 2003. Programa Hidráulico Regional 2002-2006, Pacífico Norte, Región III. (National Water Commission, Hydraulics Regional Program 2002-2006, Northern Pacific Region) Pp. 166.

[2] CNA, 2002. Norma Oficial Mexicana NOM-011-CNA-2000: Conservación del recurso agua que establece las especificaciones y el método para determinar la disponibilidad media anual de las aguas nacionales. Publicada el 7 de abril de 2002. (National Water Comisión. Official Mexican Standard NOM-011-CNA-2000, Published on April 7, 2002)

[3] DOF, 1955. Diario Oficial de la Federación, donde se publicaron los decretos de veda en la concesión y uso de aguas superficiales para la cuenca del río San Pedro, 08 de febrero de 1955. (Mexican Federal Official Journal, Legal Ordinance related to prohibition on use and assignment of surface water, on the San Pedro River Basin. Published on February 8, 1955)

[4] SRH. 1968. Boletín Hidrológico No. 30 Región Hidrológica 11, PresidioSan Pedro. Tomo I. (Ministry of Water Resources, Hydrologic Bulletin No. 30, Hydrologic Region 11, Presidio-San Pedro Rivers, Volume I). 